\title{
EVALUATION OF RISK FACTORS FOR INTRAHEPATIC CHOLESTASIS OF PREGNANCY IN PATIENTS PRESENTING TO A TERTIARY CARE CENTRE
}

\author{
Rabiah Anwar, Kashif Razzaq, Aysha Shahid, Afeera Afsheen, Amera Tariq, Irum Saleem
}

Pakistan Naval Ship Shifa Hospital, Karachi Pakistan

\begin{abstract}
Objectives: To evaluate the principal risk factors associated with development of intrahepatic cholestasis of pregnancy (ICP) in patients presenting to a tertiary care hospital.

Study Design: Case control study.

Place and Duration of Study: Department of Gynaecology and Obstetrics, Pakistan Naval Ship Shifa Hospital Karachi, from Jan to Dec 2019.

Methodology: All pregnant women with symptoms of intrahepatic cholestasis of pregnancy confirmed on history, examination and investigations were included. A comparison cohort of pregnant women with neither hepatobiliary nor medical illness associated with pregnancy was selected. Comparison of risk factors was done between both the groups.

Results: Out of 6932 obstetric patients, $90(1.29 \%)$ had intrahepatic cholestasis of pregnancy. Pruritis was cardinal symptoms in all $(100 \%)$ the patients followed by excoriation marks $(75.55 \%)$. Intrahepatic cholestasis of pregnancy was significantly found in women with multiple pregnancy ( $\mathrm{OR}=1.81 ; 95 \%$ CI 0.51-6.42), antecedent intrahepatic cholestasis of pregnancy (OR=36.81; 95\% CI 8.53-158.79), family history of intrahepatic cholestasis of pregnancy (OR=17.80; 95\% CI 2.29-137.91) and history of pruritis with obstetric cholestasis of pregnancy use (OR=16.25; 95\% CI 0.91-289.08).

Conclusion: Intrahepatic cholestasis of pregnancy was observed in less than two percent cases. Risk of intrahepatic cholestasis of pregnancy was found to be increased with multiple pregnancies, antecedent intrahepatic cholestasis of pregnancy, family history of intrahepatic cholestasis of pregnancy and history of pruritis with prior obstetric cholestasis of pregnancy use.
\end{abstract}

Keywords: Frequency, Intrahepatic cholestasis of pregnancy, Risk factors.

How to Cite This Article: Anwar R, Razzaq K, Shahid A, Afsheen A, Tariq A, Saleem I. Evaluation of Risk Factors for Intrahepatic Cholestasis of Pregnancy in Patients Presenting to A Tertiary Care Centre. Pak Armed Forces Med J 2021; 71(5): 1852-1856. doi: https://doi.org/10.51253/pafmj.v71i5.5310

This is an Open Access article distributed under the terms of the Creative Commons Attribution License (https://creativecommons.org/licenses/by-nc/4.0/), which permits unrestricted use, distribution, and reproduction in any medium, provided the original work is properly cited.

\section{INTRODUCTION}

Intrahepatic cholestasis of pregnancy (ICP) also known as obstetric cholestasis (OC) is the most common pregnancy specific liver disorder. ${ }^{1}$ ICP typically presents in third trimester. Patient complains of pruritis most commonly of the palm of the hands and soles of the feet. On investigation, liver enzymes/bile acids are elevated with or without hyperbilirubinemia. ${ }^{2}$ OC often resolve spontaneously during puerperium. ${ }^{3}$ It has benign clinical course in pregnant women but it is associated with poor perinatal outcomes such as premature delivery, meconium stained amniotic fluid and fetal death. ${ }^{4}$

Environmental, genetic and hormonal factors influence disease process. Mutation of transport proteins and bile acid receptor is an etiological factor. ${ }^{5}$ In genetically susceptible women, disease results from cholestatic effect of reproductive hormones (estrogen and progesterone). ${ }^{1}$ During third trimester when estrogen level reaches its maximum, OC appears. Women with

Correspondence: Dr Rabiah Anwar, Classified Gynaecologist, Bahria University Medical and Dental College, Karachi Pakistan

Received: 11 Sep 2020; revision received: 08 Dec 2020; accepted: 17 Dec 2020 twin pregnancies having higher level of estrogen as compared to those with singleton are more affected by ICP. ${ }^{6}$ Clinical and biochemical cholestasis is also seen with oral contraceptive pills use in some women with history of ICP. Oral progesterone treatment to prevent preterm labor can also cause $\mathrm{ICP}^{7}$. Furthermore, environmental factors such as viral hepatitis $C$ infection and selenium also influence the etiology of ICP. ${ }^{1}$

The most predictive and accurate marker for diagnosis and follow up of ICP is increased total serum bile acids level (>11 micromol/1). ${ }^{8}$ In case of non-availability of test, the diagnosis of ICP is established after exclusion of other causes of itching and abnormal liver function test. Postnatal resolution of itching and abnormal LFTs should be confirmed to establish the diagnosis 9 . The Royal College of Obstetrician and Gynaecologist (RCOG) guidelines also recommend the same. ${ }^{10}$ For obstetric cholestasis, globally recognized risk factors are previous history of obstetric cholestasis, family history of ICP, multiple pregnancy and pruritis with use of oral contraceptive pills. Local data about OC is scarce. Therefore, we carried out study to analyze risk factors for development of ICP in our obstetrics 
population. As ICP is associated with poor fetal outcome requiring NICU admission, this study will help in identifying areas where intervention should be focused on improving maternal care and perinatal outcomes thus reducing NICU load. It will also add to our research in ICP.

\section{METHODOLOGY}

The case control study was conducted in the department of Gynae/Obs, Pakistan Naval Ship Shifa (PNS) Karachi, from January to December 2019. PNS Shifa Karachi is a referral institute and a tertiary care hospital catering for large number of army and civilian personnel. A total number of 6932 women delivered during the study period.

Inclusion Criteria: This study included all the pregnant women with ICP.

Exlusion Criteria: Patients with pruritic lesions of skin, viral hepatitis, autoimmune liver disease, coagulopathies, thrombocytopenia, gallstones and cholestasis due to other reasons were excluded.

Approval from the institutional ethical committee was obtained (Ref no. ERC/2020/Med/32). Assuming $3.1 \%$ frequency of intrahepatic cholestasis of pregnancy ${ }^{2}$, a minimum sample size of 47 was calculated to provide study $80 \%$ power in assessing risk factors of obstetric cholestasis. Non-probability consecutive sampling technique was used.

Informed verbal and written consent was taken from the women before enrollment in the study and their confidentiality maintained.

Symptoms inquired were itching especially on palm of hands and soles of feet, insomnia due to itching, color of urine and stool. To rule out autoimmune cause appetite, joint pain, rash and mouth ulcers were inquired. For evaluation of risk factors, history of itching in previous pregnancy, history of multiple pregnancy, family history of intrahepatic cholestasis, history of intake of drugs that may lead to cholestasis (such as azithromycin, co-amoxiclave and carbamazepine) and history of symptoms of cholestasis with oral contraceptive pills use were explored. Detailed general physical and systemic examination was done. Our setup provides free treatment and investigations for the entitled patients. Investigations carried out were complete blood count, hepatitis B surface antigen (HBsAg), antihepatitis $C$ viral antibodies, Liver Function Test (LFT) including transaminases (aspartate aminotransferase, alanine aminotransferase), alkaline phosphatase and serum bilirubin. On suspicion, antinuclear antibo- dies (ANA) and rheumatoid (RA) factor was advised to rule out autoimmune disorders. Abdominal ultrasonography was advised to rule out gallstone and biliary duct dilatation. Due to non-availability of serum bile acid test, we made our diagnosis of OC after excluding other causes of itching and abnormal liver function. Criteria of raised serum aminotransferases (>30 $\mathrm{iu} / \mathrm{l})$ and alkaline phosphatase $(>300 \mathrm{IU} / \mathrm{L})$ in patients with pruritis of pregnancy in absence of any dermatosis, viral hepatitis, cholelithiasis and autoimmune liver disorder was used for diagnosis of ICP. Out of 90 $(1.29 \%)$ ladies were diagnosed to have obstetric cholestasis. Their demographic, clinical and laboratory parameters were recorded in a proforma.

A control group was selected, which included pregnant women with neither hepatobiliary nor medical illness associated with pregnancy. The risk factors for development of ICP assessed were multiple gestations, previous history of ICP, family history of OC and itching associated with OCPs use. Comparison of risk factors among cases and control was done.

Follow up of patients was done according to antenatal visit protocol. Women requiring intensive fetomaternal monitoring were hospitalized. Delivery was done according to gestational age. After 42 days of delivery, women were followed up for confirming resolution of symptoms and laboratory parameters.

All data was maintained and analyzed on SPSS 19. Mean \pm SD were calculated for quantitative data. Frequency and percentage were calculated for qualitative data. The chi-square test and t-test were used to compare the dichotomous variables. Risk calculation was determined via Odd ratio, with 95\% confidence interval (CI). Difference was considered significant at $p \leq 0.05$.

\section{RESULTS}

During study period, total 6932 patients were delivered; out of them 90 (1.29\%) ladies had obstetric cholestasis. All of them presented with itching, while $68(75.55 \%)$ developed excoriation marks due to itching. Furthermore, $28(31.11 \%)$ of them had history of loss of appetite, $44(48.88 \%)$ had dark colored urine, $35(38.88 \%)$ developed burning of skin and $2(2.22 \%)$ developed yellow discoloration of sclera. Table-I show symptoms and signs in obstetric cholestatic patients.

All ladies of obstetric cholestasis had raised LFTs as depicted in Table-II. Mean Aspartate Aminotransferase level observed was $44.866 \pm 19.15$ and Alanine Aminotransferase level was $47.60 \pm 17.23$. All the cases 
had raised Alkaline phosphatase levels with $376.72 \pm$ 87.92 .

Table-I: Evaluation of symptoms and signs in obstetric cholestatic patients.

\begin{tabular}{|c|c|c|c|}
\hline Symptoms & n (\%) & Signs & n (\%) \\
\hline Pruritis & $90(100 \%)$ & $\begin{array}{l}\text { Excoriation } \\
\text { mark }\end{array}$ & $68(75.55 \%)$ \\
\hline Loss of Appetite & $28(31.11 \%)$ & Jaundice & $2(2.22 \%)$ \\
\hline $\begin{array}{l}\text { Dark colored } \\
\text { urine }\end{array}$ & $44(48.88 \%)$ & & \\
\hline \begin{tabular}{|l|l} 
Burning of skin & \\
\end{tabular} & \begin{tabular}{|l|l}
$35(38.88 \%)$ & \\
\end{tabular} & & \\
\hline \multicolumn{4}{|c|}{ Table-II: Liver function tests in obstetric cholestasis. } \\
\hline $\begin{array}{l}\text { Liver Function } \\
\text { Tests }\end{array}$ & $\begin{array}{c}\text { Normal Value } \\
\text { Non-Pregnant } \\
\text { value } \\
\text { (Upper Limit) }\end{array}$ & \begin{tabular}{c|c} 
e & Normal \\
t & Value in \\
Pregnancy \\
(Upper \\
Limit) \\
\end{tabular} & $\underset{\text { SD }}{\text { Mean } \pm}$ \\
\hline $\begin{array}{l}\text { Aspartate amino- } \\
\text { transferase (iu/L) }\end{array}$ & 40 & 30 & $\begin{array}{r}44.866 \\
\pm 19.15 \\
\end{array}$ \\
\hline $\begin{array}{l}\text { Alanine amino- } \\
\text { transferase (iu/L) }\end{array}$ & 40 & 32 & $\begin{array}{c}47.60 \pm \\
17.23 \\
\end{array}$ \\
\hline $\begin{array}{l}\text { Alkaline phos- } \\
\text { phatase (iu/L) }\end{array}$ & 130 & 300 & $\begin{array}{r}376.72 \\
\pm 87.92 \\
\end{array}$ \\
\hline $\begin{array}{l}\text { Bilirubin } \\
(\mathrm{mmol} / \mathrm{l})\end{array}$ & 17 & 17 & $\begin{array}{l}20 \pm \\
6.85\end{array}$ \\
\hline \multicolumn{4}{|c|}{ Table-III: Characteristics of study groups. } \\
\hline Characteristics & $\begin{array}{c}\text { Obstetric } \\
\begin{array}{c}\text { Cholestasis } \\
\text { Group }\end{array}\end{array}$ & $\begin{array}{l}\text { Control } \\
\text { Group }\end{array}$ & $\begin{array}{c}p \text { - } \\
\text { value }\end{array}$ \\
\hline Age (mean \pm SD) & $25.48 \pm 1.73$ & $25.08 \pm 1.44$ & 0.510 \\
\hline \multicolumn{4}{|l|}{ Nullipara } \\
\hline $\begin{array}{l}\text { Parity } \\
\text { multipara }\end{array}$ & $\begin{array}{l}27(30 \%) \\
63(70 \%) \\
\end{array}$ & $\begin{array}{l}46(51.11 \%) \\
44(48.88 \%) \\
\end{array}$ & 0.004 \\
\hline $\begin{array}{l}\text { Gestation at prese- } \\
\text { ntation }(\text { mean } \pm S D)\end{array}$ & $35.2 \pm 1.96$ & $34.67 \pm 1.6$ & 0.392 \\
\hline
\end{tabular}

Mean age of obstetric cholestatic patients was $25.48 \pm 1.73$ and mean age of control group was 25.086 \pm 1.44 . In obstetric cholestatic group $30 \%$ women were nullipara and $70 \%$ were multipara. Whereas, in control group $51.11 \%$ were nullipara and $48.88 \%$ were multi- para. Gestational age at presentation was $35.2 \pm 1.96$ in obstetric cholestatic group and $34.67 \pm 1.6$ in control group (Table-III).

Then four different risk factors under consideration were analyzed among both the groups. We found all of them significantly associated with obstetric cholestasis as odds ratio was $>1$ as shown in Table-IV.

\section{DISCUSSION}

Intrahepatic cholestasis of pregnancy (ICP) affects $0.2-2 \%$ of pregnant women worldwide but its incidence varies with regard to both ethnicity and geography ${ }^{11}$. In UK, $0.7 \%$ of all pregnant women are affected ${ }^{1}$. In Asian women, its incidence is twice as compared to white European women ${ }^{1}$. In Nepal, 1.15\% incidence has been reported, ${ }^{9}$ whereas in India the reported incidence is about $1 \% .^{12}$

The frequency of ICP in our study was $1.29 \%$ but Hafeez reported 3.1\% frequency which is almost double to our finding. ${ }^{2}$

In our study, main presentation was itching. All patients presented with pruritis mostly on palm of the hands and soles of the feet but some had generalized pruritis. Padmaja and Geenes had same findings. ${ }^{12,1}$ Hafeez observed pruritis in $83 \%$ cases. $^{2}$

The secont most common presenting complaint in our study was excoriation mark due to itching. We observed excoriation mark in $75.5 \%$ of patients whereas Hafeez found in $65 \%$ patients. $^{2}$

We found 2 cases of clinical jaundice. Hafeez observed jaundice in 5 cases (16.7\%) 2 but Padmja found no case of jaundice. ${ }^{12}$

As aspartate aminotrasferase (AST) is also produced by skeletal and cardiac muscles, alanine aminotransferase (ALT) is more specific to liver than AST. ${ }^{1}$

Table-IV: Comparison of risk factors among obstetric cholestatic and control group.

\begin{tabular}{|c|c|c|c|c|c|}
\hline Characteristics & $\begin{array}{l}\text { Obstetric Cholestasis } \\
\text { Group, } \mathbf{n}(\%)\end{array}$ & $\begin{array}{c}\text { Control Group } \\
n(\%)\end{array}$ & $p$-value & Odds Ratio & $\begin{array}{c}\begin{array}{c}95 \% \text { Confidence } \\
\text { Interval }\end{array} \\
\end{array}$ \\
\hline \multicolumn{6}{|c|}{ Multiple Pregnancy } \\
\hline $\begin{array}{l}\text { Yes } \\
\text { No }\end{array}$ & $\begin{array}{c}7(7.77 \%) \\
83(92.22 \%)\end{array}$ & $\begin{array}{c}4(4.44 \%) \\
86(93.47 \%)\end{array}$ & 0.351 & 1.8133 & 0.51 to 6.42 \\
\hline \multicolumn{6}{|c|}{ Previous History of ICP } \\
\hline $\begin{array}{l}\text { Yes } \\
\text { No }\end{array}$ & $\begin{array}{l}41(45.55 \%) \\
49(54.44 \%)\end{array}$ & $\begin{array}{c}2 \\
88(97.77 \%)\end{array}$ & 0.001 & 36.8163 & 8.53 to 158.79 \\
\hline \multicolumn{6}{|c|}{ Family History of ICP } \\
\hline $\begin{array}{l}\text { Yes } \\
\text { No } \\
\end{array}$ & $\begin{array}{l}15(16.66 \%) \\
75(83.33 \%) \\
\end{array}$ & $\begin{array}{c}1(1.11 \%) \\
89(98.88 \%)\end{array}$ & 0.001 & 17.80 & 2.29 to 137.91 \\
\hline \multicolumn{6}{|c|}{ History of pruritis with oral contraceptive pill use } \\
\hline $\begin{array}{l}\text { Yes } \\
\text { No }\end{array}$ & $\begin{array}{c}7(7.77 \%) \\
83(92.22 \%)\end{array}$ & $\begin{array}{c}- \\
0(100 \%)\end{array}$ & 0.007 & 16.257 & 0.91 to 289.08 \\
\hline
\end{tabular}


During interpretation of liver function tests in pregnant women, pregnancy specific ranges should be used. ${ }^{13}$

In this study, the most frequent abnormality encountered in LFTs was elevated transaminases which were raised in (98\%) of women. Padmaja observed raised transaminases in $97.8 \%$ of women. ${ }^{12}$ We found mean alanine aminotransferase $47.60 \pm 17.23$. Singh found aminotransferases were increased by 2-3 times. ${ }^{14}$

In our study, alkaline phosphatase levels were raised three to four times above the control in OC pregnancies. Similar findings were observed by Singh. ${ }^{14}$

We observed mean bilirubin $20 \pm 6.85 \mathrm{mmol} / 1$ in obstetric cholestatic patients. Singh et al observed no significant rise in serum bilirubin, ${ }^{14}$ whereas Padmaja et al observed mild hyperbilirubinemia in $18.4 \%$ cases and highest bilirubin level noted was $2.8 \mathrm{mg} / \mathrm{dl} .{ }^{12}$ Geenes et al found elevated levels of bilirubin in approximately $10 \%$ of women with ICP1.

As serum bile acid assessment is not available, we could not determine the level in our patients.

It is believed that OC is mostly observed in women with multifetal pregnancy, pevious history of ICP, ${ }^{15}$ older age, history of itching with oral contraceptive pill use, ${ }^{16}$ and in sisters of affected women. ${ }^{17} \mathrm{We}$ did comparison of these risk factors among ICP patients and pregnant women having no comorbids.

Some authors have reported that women of relatively advanced age ( $>35$ yrs) are at increased risk of developing obstetric cholestasis. ${ }^{1}$ In our study, OC patients had mean age of $25.48 \pm 1.73$ and there was no significant difference between 2 groups in maternal age. Hafeez et al found $29.8 \pm 4.76$ years mean age of ICP patient. ${ }^{2}$ Same was observed by Singh. ${ }^{14}$ Padmaja et al observed mean age of 28.7 with no difference in age in both case and control group. ${ }^{12}$

We found $30 \%$ of ICP were nullipara and $70 \%$ were multipara. Whereas in control group 51.11\% were, nullipara and $48.88 \%$ were multipara. Hafeez found $2.5 \pm 1.36$ mean numbers of previous pregnancies in ICP patients. ${ }^{2}$

All patients presented in $3^{\text {rd }}$ trimester of pregnancy. Mean duration of pregnancy was $35.2 \pm 1.96$ weeks. Whereas Hafeez et al observed $33.1 \pm 3.78$ weeks mean duration of pregnancy. ${ }^{2}$ Geenes et al observed that approximately $80 \%$ of women with ICP presents after 30 weeks of gestation ${ }^{1}$. However, there are reports of earlier onset in women with multifetal pregnancy. Padmaja et al also diagnosed $71.1 \%$ cases of OC in third trimester. ${ }^{12}$

In this study, $7.77 \%$ of ICP women had twin pregnancy whereas $4.44 \%$ of control group had multifetal pregnancy. Arrese found five times greater prevalence of ICP in twin pregnancies. ${ }^{7}$ However, Singh found no twin in ICP group. ${ }^{14}$

We observed that $45.55 \%$ patients had history of OC in previous pregnancies. Kawakita found 30\% recurrence $^{18}$. Padmaja observed $64.3 \%$ recurrence rate. ${ }^{12}$ Arrese says recurrence rate of ICP varies between 40$60 \%$ of pregnancies and there is great variation in intensity of disease in subsequent pregnancies. ${ }^{7}$ Hafeez observed $10 \%$ patients had past ICP history 2 but Singh found that only two women had previous OC history. ${ }^{14}$

We observed $16.66 \%$ patients had history of OC in family. Hafeez found one (3.2\%) patient had family history of $\mathrm{ICP}^{2}$. No family history could be elicited in ICP group by Singh ${ }^{14}$. Whereas, family history of ICP was observed in $16 \%$ of cases by Arrese 7 and in $14 \%$ of cases by Geenes et al. ${ }^{1}$

Oral contraceptive pills with high estrogen content can lead to cholestatic picture closely resembling $\mathrm{ICP}^{7}$. We observed $7(7.77 \%)$ patients had history of pruritis with OCP use. Hafeez et al found one (3.2\%) wo-men had history of pruritis with contraceptive pill use before pregnancy. ${ }^{2}$

Diagnosis and management of ICP is important in reducing fetomaternal morbidity and mortality. ${ }^{19}$ The major contribution of this study is to create awareness about the burden of this disease in our country and to make way for further research. Consequently, this will help in improving fetomaternal outcome.

\section{LIMITATION OF STUDY}

Non-availability of bile acids was major limitation of our study. We diagnosed ICP by clinical features and excluding other causes of itching in the presence of abnormal liver function tests. In addition, this study was conducted in a tertiary care hospital which is not representative of the country. Since most women in Pakistan deliver at home, the burden of ICP can be expected to be much higher outside the hospital setting.

\section{CONCLUSION}

We conclude that conditions that should alert doctors to the possible presence of ICP in pregnant women include: 3rd trimester, multiple gestation, previous history of ICP, family history of $\mathrm{OC}$ and itching with prior OCP use.

Conflict of Interest: None. 


\section{Authors' Contribution}

RA: Direct Contribution, KR: Conception and data analysis, AS: Facilitation, AA: Facilitation, AT: Facilitation, IS: Facilitation.

\section{REFERENCES}

1. Geenes V, Williamson C, Chappell LC. Intrahepatic cholestasis of pregnancy. Obstet Gynaecol 2016; 18(4): 273-281.

2. Hafeez M, Ansari A, Perveen S, Salamat A, Aijaz A. Frequency of intrahepatic cholestasis of pregnancy in Punjab Pakistan: A single centre study. J Pak Med Assoc 2016; 66(2): 203-206.

3. Mohan M, Antonios A, Konje J, Lindow S, Syed MA, Akobeng A. Stillbirth and associated perinatal outcomes in obstetric cholestasis: a systematic review and meta-analysis of observational studies. Eur J Obstet Gynecol Reprod Biol X 2019; 3(1): 100026.

4. Herrera CA, Manuck TA, Stoddard GJ, Varner MW, Esplin S, Clark EA, et al. Perinatal outcomes associated with intrahepatic cholestasis of pregnancy. J Matern Fetal Neonatal Med 2018; 31(14): 1913-1920.

5. Onofrio FQ, Hirschfield GM. the pathophysiology of cholestasis and its relevance to clinical practice. Clin Liver Dis 2020; 15(3): 110-114.

6. Shan D, Hu Y, Qiu P, Mathew BS, Chen Y, Li S, et al. Intrahepatic cholestasis of pregnancy in women with twin pregnancy. Twin Res Hum Genet 2016; 19(6): 697-707.

7. Arrese M, Reyes H. Intrahepatic cholestasis of pregnancy: A past and present riddle. Ann Hepatol 2006; 5(3): 202-305.

8. Cui D, Zhong Y, Zhang L, Du H. Bile acid levels and risk of adverse perinatal outcomes in intrahepatic cholestasis of pregnancy: a meta analysis. J Obstet Gynaecol Res 2017; 43(9): 14111420.
9. Pokhrel S, Ghimire A, Shankar G, Chhetry M, Kumar M. FetoMaternal outcomes in intrahepatic cholestasis in pregnancy in a tertiary care centre in Eastern. JoNMC 2016; 5(8): 20-25.

10. Royal College of Obstetrician and Gynaecologists. Obstetric Cholestasis RCOG Green Top guidelines. No 43 April 2011, [Internet] Available from: www. https://www.rcog.org.uk/en/ guidelines-research-services/guidelines/gtg43/ (Accessed on Jan 10, 2020)

11. Kulsoom O, Ishtiaq $S$, Hussain R. Intrahepatic Cholestasis Of Pregnancy-A Review. Pak J Med Dent 2017; 6(4): 47-51.

12. Padmaja M, Bhaskar $P$, Kumar G, Seetha R. A study of obstetric cholestasis. J Obstet Gynecol India 2010; 60(3): 225-231.

13. Wood AM, Livingston EG, Hughes BL, Kuller JA. Intrahepatic cholestasis of pregnancy: a review of diagnosis and management. Obstetrical Gynecol sur 2018; 73(2): 103-109.

14. Singh G, Sidhu K. Cholestasis of pregnancy: A Prospective study. Med J Arm For Ind 2008; 64(4): 343-345.

15. Menżyk T, Bator M, Derra A, Kierach R, Kukla M. The role of metabolic disorders in the pathogenesis of intrahepatic cholestasis of pregnancy. Clin Exp Hepatol 2018; 4(1): 217-221.

16. Kumar $S$, Puri P, Gujral K. Intrahepatic cholestasis of pregnancy. Curr Med Res Pract 2018; 8(6): 230-234.

17. Vitale G, Gitto S, Vukotic R, Raimondi F, Andreone P. Familial intrahepatic cholestasis: New and wide perspectives. Dig Liver Dis 2019; 1(7): 922-933.

18. Kawakita T, Parikh LI, Ramsey PS, Zeymo A, Fernandez M, Smith S, et al. Predictors of adverse neonatal outcomes in intrahepatic cholestasis of pregnancy.HHS public access. Am J Obs Gynecol 2015; 213(4): 1-16.

19. Smith DD, Rood KM. Intrahepatic Cholestasis of Pregnancy. Clin Obstet Gynecol 2020; 63(1): 134-151. 